\title{
PRELIMINARY RESEARCH IN MICROORGANISM PRETREATMENT OF BIOMASS FOR LIGNOCELLULOSE DEGRADATION
}

\author{
Magdalena-Laura Toma, Gheorghe Voicu, Mariana Ferdes, Mirela-Nicoleta Dinca \\ University Politehnica of Bucharest, Romania \\ lauratoma2002@yahoo.com,ghvoicu_2005@yahoo.com,marianaferdes@yahoo.com, \\ mirela_dilea@yahoo.com
}

\begin{abstract}
Obtaining bioethanol from lignocellulosic substrates is conditioned by degradation of vegetal substrates as much as possible. A fungal strain of Sporotrichumpulverulentumwas characterized morphologically and from enzyme production point of view in order to degrade corn stalks and wheat straw to obtain fermentable sugars. The production of hydrolytic enzymes (cellulases, amylases, proteases, lipases) was tested by qualitative analysis methods on specific culture media. The production of laccase, the enzyme involved in lignin degradation, was evaluated using guaiacol as substrate. The Sporotrichumpulverulentum strain was cultured on a rotary incubator at $150 \mathrm{rpm}$ and $30^{\circ} \mathrm{C}$ for 3 days to obtain the biomass used for inoculating the bioreactor. Substrate was physicochemically analysed for total solids (TS) and a dimensional analysis of substrate particles before and after fungal decompositionwas also performed. Corn stalks and respectively wheat straw were mixed with $3 \mathrm{~L}$ of water in a laboratory bioreactor type MINIFORS. The inoculation was carried out with $300 \mathrm{~mL}$ Sporotrichumpulverulentum culture obtained in the rotating incubator and the action of the fungal strain on corn stalks and wheat straw was followed for 3 days in the MINIFORS bioreactor at $30^{\circ} \mathrm{C}, 200 \mathrm{rpm}$ at a flow rate of $2 \mathrm{~L} \cdot \mathrm{min}^{-1}$. Samples were collected and substrate mass reduction, $\mathrm{pH}$, sugar content by DNS method and dry matter were analysed. The results demonstrate that the pretreatmentwith the enzymes synthesized by Sporotrichumpulverulentum in liquid medium of lignocellulosic material resulted from agricultural activities can be further used, with excellent results, in obtaining bioethanol.
\end{abstract}

Keywords: microbial pretreatment, lignin and cellulose degradation, agricultural wastes, bioethanol.

\section{Introduction}

Due to the limited quantities of conventional energy resources, researchers are more and more involved in obtaining energy from vegetal biomass that is abundant almost all over the globe. Nevertheless, it does not mean that energy is going to be easy to extract knowing that biomass contains lignocellulose, which is hard to decompose.Lignocellulose represents almost half of plant matter and consists of cellulose (40-60\%), hemicellulose (20-40\%) and lignin (10-25 \%) [1]. In case of wheat straws, these polymers are comprised between $29-40 \%$ for cellulose, $20-32 \%$ for hemicellulose and 12-21\% for lignin [2-5]. As for corn stalk, percentage quantities of polymers are $38-47 \%$ for cellulose, $25-32 \%$ for hemicellulose and 3-21\% for lignin $[1 ; 6]$. Pretreatments applied to biomass can be mechanical, chemical, thermal, thermo-chemical or biological. Nevertheless, the first four pretreatment methods imply relatively high costs and have a significant impact on the environment. That is why the biological pretreatment applied to lignocellulosic wastes is gaining terrain because it is easy to apply, cost effective and has a low impact on environment $[7 ; 8]$. The purpose of the study was degradation of lignocellulosic material to fermentable sugars in the presence of Sporotrichumpulverulentum enzymes.

\section{Materials and methods}

For the purpose of these experiments, the used microorganism was a Sporotrichumpulverulentum strain from the collection of MicrobiologyLaboratory of the Faculty of Biotechnical Systems Engineering, University "Politehnica" of Bucharest. The fungal strain of Sporotrichumpulverulentumwas cultivated on Potato Dextrose Agar (potato extract $4.0 \mathrm{~g} \cdot \mathrm{l}^{-1}$, glucose $20.0 \mathrm{~g} \cdot \mathrm{l}^{-1}$, agar $\left.15.0 \mathrm{~g} \cdot \mathrm{l}^{-1}\right)$ in tubes at $25^{\circ} \mathrm{C}$ for 7 days.

The Sporotrichumpulverulentum strain was chosen from several genera of fungal species known for their ability to produce enzymes able to degrade the lignocellulosic substrates. Next, fungus mycelium from each tube was mixed with sterile water and transferred into $500 \mathrm{~mL}$ sterile Erlenmeyer flasks containing $300 \mathrm{~mL}$ of Potato Dextrose Broth medium, closed with a cotton plug. Then, the flasks were incubated on the orbital incubator Thermoshake Gerhardt for $72 \mathrm{~h}$ at $30^{\circ} \mathrm{C}$ with $150 \mathrm{rpm}$. The culture obtained on the orbital incubator was inoculatedin a volume of 31 medium containing agricultural biomass, sterilized at $121^{\circ} \mathrm{C}$ for 15 minutes. 
The wheat straws and corn stalks used in this study were collected from a farm in TeleormanCounty, Romania, in summer - autumn 2017. The tested biomass was grinded at $1 \mathrm{~mm}$ using the laboratory mill Pulverisette 19 and $50 \mathrm{~g}$ of biomass, finely grinded, inserted into the bioreactor for each experiment[7].

Cultivation of Sporotrichumpulverulentum strains was performed in a 5 L MINIFORS laboratory bioreactor in the following conditions: mixing rate of $200 \mathrm{rpm}$, temperature of $30^{\circ} \mathrm{C}$ and airflow of $21 \cdot \mathrm{min}^{-1}$. The experiments lasted a week and samples were taken every day.

The wheat straw and corn stalk samples were analyzed at a Bel Photonics microscope, before and after the experiments. In each case sugar concentration was measured using the method, in which 3.5dinitrosalicylic acid (DNS) is used [9]. The absorbance was measured at $540 \mathrm{~nm}$ using the T92+ UV VIS spectrophotometer, PG Instruments. The $\mathrm{pH}$ of the liquid samples taken at certain intervals of time was determined using a $\mathrm{pH}$ meter type Hanna Instruments.

The fungal strain was characterized in terms of enzyme production through the semiquantitative analysis using specific media in Petri dishes. Amylases were assessed in a medium containing soluble starch as a carbon source. Adding Lugol solution, the zone of hydrolysis remained uncoloured, whereas the non-hydrolysed starch was coloured dark blue. The proteolytic enzymes were highlighted on a nutrient medium with casein; the clarification of agar was due to the hydrolysis of casein around the colonies. The lipolytic fungi produced an opaque zone due to the formation of calcium salts in a nutrient agar supplemented with Tween 80 and $\mathrm{CaCl}_{2}$. Cellulolytic colonies hydrolysed the cellulose contained in the culture medium and produced a clarified hydrolysis zone [10]. The biosynthesis of laccases was assessed on Potato Dextrose Agar supplemented with $0.04 \%$ guaiacol. The reddish brown zones around the fungal colonies are due to the oxidation of guaiacol to a coloured product [11-13].

The solid portion of the culture medium was separated by filtration on Wattman filter paper no. 1 . The resulting wet biomass was weighed and then the dry matter content was determined with a KERN RH 123-3 thermobalance.

\section{Results and discussion}

The Sporotrichumpulverulentum strain was characterized by the qualitative method of producing degradative enzymes for the substrate: amylase, protease, cellulases, lipases, and laccases. The qualitative assessment of enzyme production is represented as a ratio between the diameter of the highlighted zone and the diameter of the colony. The Sporotrichumpulverulentum strain had a cellulolytic index of 2.4/1.6, proteolytic index of 2.8/1.8 laccase index of 2.6/2.3 and did not produce amylases and lipases, as determined by semiquantitative methods for enzyme testing.

The $\mathrm{pH}$ and $\mathrm{pO}_{2}$ values recorded by the MINIFORS software are shown in Figure 1 showing that for the two substrates the $\mathrm{pH}$ is decreasing, ranging from 7.21 to 6.81 for wheat straw and from 7.58 to 6.99 for corn stalks. Dissolved oxygen also had decreasing values in both cases due to the development of aerobic fungal strain.

The samples taken from the culture in the MINIFORS bioreactor were analyzed from the point of view of the sugar content by the DNS method. The sugar concentration was calculated using a calibration curve for glucose and the results are shown in Figure 2.

The values of sugar content for both wheat straws and corn stalks demonstrated that the action of exoenzymes of fungal strain of Sporotrichumpulverulentum was significant. For straw the final glucose concentration was $0.36 \mathrm{mg} \cdot 1^{-1}$ and for corn stalks it was $0.57 \mathrm{mg} \cdot \mathrm{l}^{-1}$ after 7 days of action on the agricultural substrate. These values are confirmed by the loss of biomass after the fungal treatment, as can be seen in Table 1 .

The degradative action on Sporotrichumpulverulentum strain was demonstrated by the glucose accumulation in the culture and by the significant reduction of biomass. The calculated values of dry biomass before and after fungal treatment have been compared. The microscope images of substrate particles before and after the action of fungal enzymes are shown in Figure 3.

From all the obtained results, namely: the concentration of glucose in the liquid culture, total quantity of remaining biomass after filtration, microscopic appearance of the lignocellulosic material, it is obvious that this kind of enzymatic pretreatment can be applied after the necessary improvements 
and cost estimation.
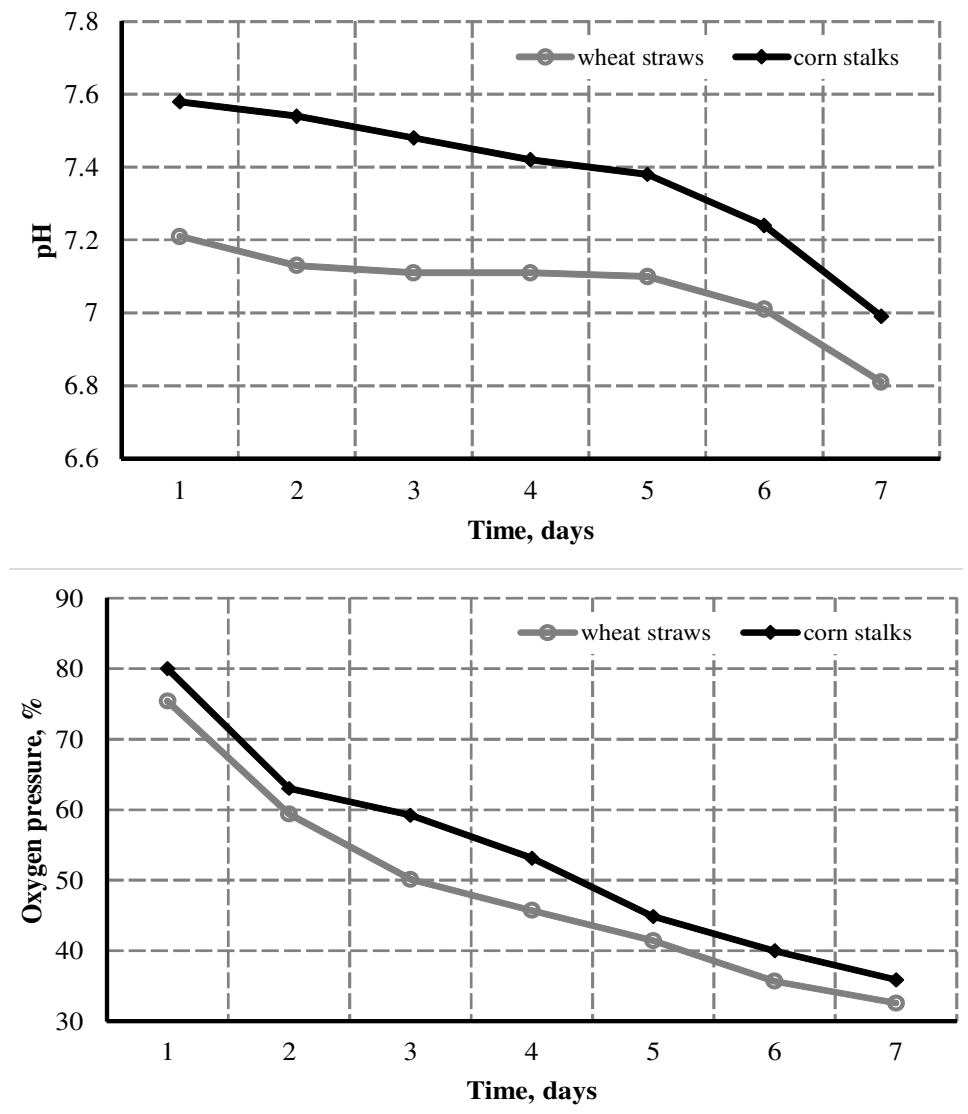

Fig. 1. Variation of $\mathbf{p H}$ and oxygen pressure over time

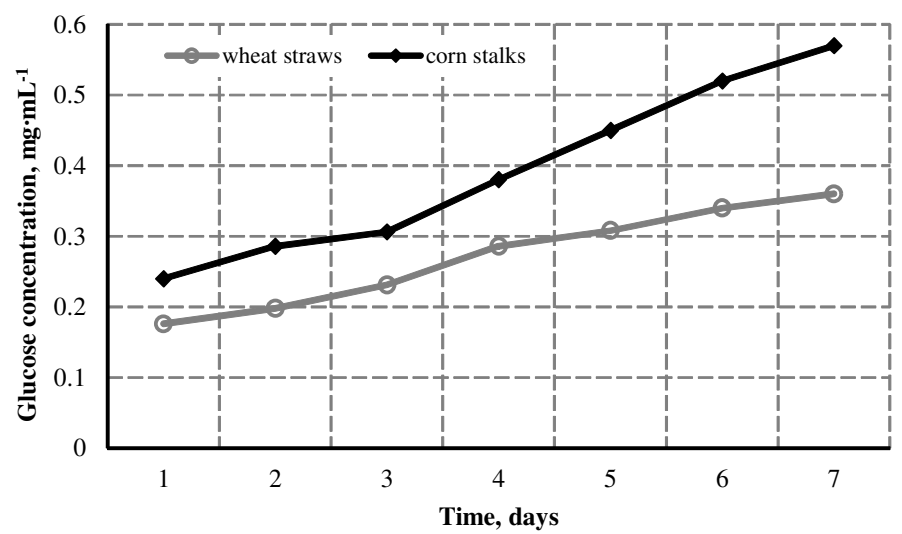

Fig. 2. Glucoseconcentrationfor used substrates during experiments

Although the amount of glucose released from lignocellulosic material has no grate value, the decreaseof biomass in terms of dry matter with a percentage of $14-16 \%$ seems promising. For cost reductions, pretreatment in liquid cultures could be replaced with pretreatment in a semi-dry culture.

\section{Determination of remaining biomass}

Table 1

\begin{tabular}{|l|c|c|c|c|}
\hline Substrate & $\begin{array}{c}\text { Total quantity of } \\
\text { remaining biomass } \\
\text { after filtration, } \mathbf{g}\end{array}$ & Dry mater, \% & Total dry biomass, $\mathbf{g}$ & $\begin{array}{c}\text { Percentage reduction } \\
\text { after microbial } \\
\text { degradation, \% }\end{array}$ \\
\hline Wheat straw & 213.1 & 92.36 & 39.27 & 14.96 \\
\hline Corn stalks & 197.4 & 92.03 & 38.73 & 15.83 \\
\hline
\end{tabular}




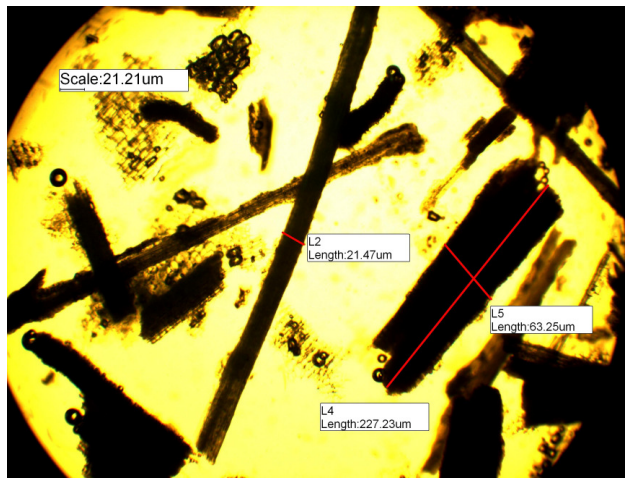

a) before fungal enzyme action

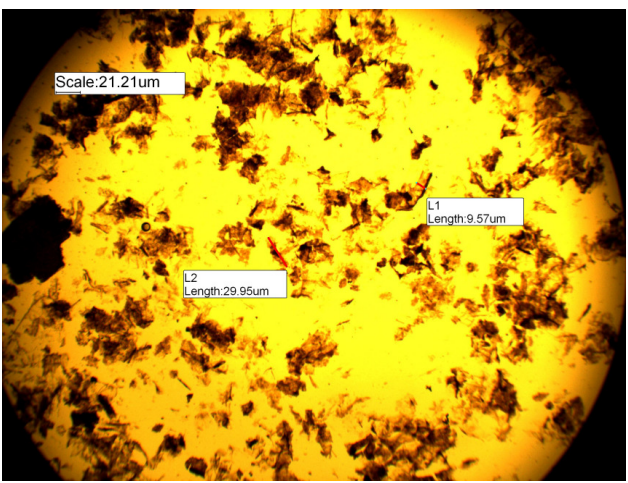

b) after fungal enzyme action

Fig. 3. Microscope images of corn stalk particles

\section{Conclusions}

1. The fungal strain of Sporotrichumpulverulentumwas characterized in terms of cellulase, laccase, protease, amylase, and lipase production.

2. Two types of agricultural by-products (wheat straws and corn stalks) have been tested as substrate in the culture of Sporotrichumpulverulentum in a laboratory MINIFORS bioreactor.

3. The degradative action of fungal strain was demonstrated through the glucose production in culture and dry biomass reduction.

4. The results of this study revealed that enzymatic pretreatment can be applied after the necessary improvements and cost estimation.

5. After pretreatment of lignocellulosic material with enzymes synthesized by Sporotrichumpulverulentum in liquid medium, biomass decrease was noticed with 14-16\% in the dry matter content.

\section{Acknowledgements}

This work was funded by the Executive Agency for Higher Education, Research, Development and Innovation Funding, within the project entitled "Optimizing the composition of biomass mixtures for obtaining high quality pellets”, ctr. 24 BG/2016 (code PN-III-P2-2.1-BG-2016-0266), Romania.

\section{References}

[1] Rastogi M., Shrivastava S. Recent advances in second-generation bioethanol production: An insight to pretreatment, saccharification and fermentation processes. Renewable and Sustainable Energy Reviews, no. 80, 2017, pp. 330-340.

[2] Sánchez C. Lignocellulosic residues: Biodegradation and bioconversion by fungi. Biotechnology Advances, no. 27, 2009, pp. 185-194.

[3] Menon V., Rao M. Trends in bioconversion of lignocellulose: Biofuels, platform chemicals \&biorefinery concept. Progress in Energy and Combustion Science, no. 38, 2012, pp. 522-550.

[4] Bajpai P. Single cell protein production from lignocellulosic biomass, SpringerBriefs in Green Chemistry for Sustainability, Springer Singapore, 2017, 78 p.

[5] Prasad S., Singh A., Joshi H.C. Ethanol as an alternative fuel from agricultural, industrial and urban residues. Resources, Conservation and Recycling, no. 50, 2007, pp. 1-39.

[6] Dungani R., Karina M., Subyakto, Sulaeman A., Hermawan D., Hadiyane A. Agricultural Waste Fibers Towards Sustainability and Advanced Utilization: A Review. Asian J. Plant Sci., no.15, 2016, pp. 42-55.

[7] Dincă M., Ferdeş M., Zăbavă B., Paraschiv G.,Ungureanu N., Vlăduț V.,Moiceanu G. Lignocellulosic biomass pretreatment by hydrolytic fungal strains. $46^{\text {th }}$ International Conference "Actual Tasks on Agricultural Engineering", February 27 - March 2, 2018, Opatija, Croatia, pp. 349-358.

[8] Wan C., Li Y. Fungal pretreatment of lignocellulosic biomass. Biotechnology Advances, no. 30, 2012, pp. 1447-1457. 
[9] Miller G.L. Use of dinitrosalicylic acid reagent for determination of reducing sugar, Anal. Chem., no. 31,1959 , pp. $426-428$

[10] Guiraud J., Galzy P. L'analyse microbiologique dans les industries alimentaires, Les Editions de l'Usine Nouvelle-Paris, 1980.

[11]Ferdeş M., Dincă M., Zăbavă B., Paraschiv G., Munteanu M., Ionescu M. Laccase enzyme production and biomass growth in liquid cultures of wood-degrading fungal strains. $46^{\text {th }}$ International Conference "Actual Tasks on Agricultural Engineering", February 27 - March 2,2018, Opatija, Croatia, pp. 341-388

[12] Kalra K., Chauhan R., Shavez M., Sachdeva S. Isolation of laccase producing Trichoderma spp. and effect of $\mathrm{pH}$ and temperature on its activity. International Journal of ChemTech Research, no. 5, 2013, pp. 2229-2235.

[13]El Monssef R.A., Hassan E.A., Ramadan E.M. Production of laccase enzyme for their potential application to decolorize fungal pigments on aging paper and parchment, Annals of Agricultural Science, no. 61, 2016, pp. 145-154. 